\title{
Preliminary investigation of transesterified waste cooking oil (WCO) as a biodiesel
}

\author{
R. C. Nnamani ${ }^{1}$, P. N. Okwu ${ }^{1}$, B. John ${ }^{1}$ and O. J. Abayeh ${ }^{1 *}$. \\ ${ }^{1}$ Department of Pure and Industrial Chemistry, University of Port Harcourt, Port Harcourt, Rivers State. \\ Nigeria. \\ *Corresponding Author's email: oviabayeh@gmail.com \\ Received 02 August 2020; accepted 09 August 2020, published online 28 August 2020
}

\begin{abstract}
This research focuses on the production of cheap biodiesel from waste cooking oil [WCO], using the transesterification method. A disadvantage of biodiesel produced from virgin oils is that it is still more expensive than D2 petroleum diesel [diesel sold in filling stations]. The trust therefore of this study is the production of relatively cheap biodiesel, from a cheap feedstock. The conversion of the WCO involved the use of excess methanol and potassium hydroxide (as a homogenous catalyst), in a separatory funnel with vigorous agitation for 30 mins at a temperature of $\left(40{ }^{\circ} \mathrm{C}\right)$. The mixture was thereafter allowed to stand overnight, and two layers were observed. The upper biodiesel [waste cooking oil methyl esterWCOMe] layer was purified by washing with water $[10 \mathrm{ml} \times 5]$ and dried (anhydrous sodium sulphate). Improvised procedures were used to determine the following fuel quality parameters (viscosity, flash point, cloud point and pour point) and afforded $29.8 \mathrm{sec}, 240{ }^{\circ} \mathrm{C}, 1.0{ }^{\circ} \mathrm{C}$ and $0.8{ }^{\circ} \mathrm{C}$ respectively. The reaction was conducted within 30 mins at $40{ }^{\circ} \mathrm{C}$. Palm kernel oil methyl ester [PKOMe] was produced from palm kernel oil [PKO] using the same process for WCOMe and the cost of production based on feedstock price only compared. Use of WCO feedstock drastically reduced the production cost of WCOMe when compared to palm kernel oil methyl ester [PKOMe]. Production cost of WCOMe was free compared to $\mathrm{N} 520.83 \mathrm{~L}^{-1}$ for PKOMe. The presence of fatty acid methyl esters in WCOMe and PKOMe was confirmed by GC. Waste cooking oil as feedstock for biodiesel should therefore be encouraged as it affords a relatively cheap fuel and remediates the disposal of WCO as an environmental hazard.

Keywords- Waste Cooking Oil, Transesterification, waste cooking oil methyl ester, fuel quality parameters

\section{Introduction}

Fossil fuels as a source of energy have played a prominent role in global economy with negative impacts on the environment, being the dominant source of air pollution, emission of greenhouse gases, etc. [1]. High consumption and nonrenewability of petroleum means it will soon be exhausted.

Today petroleum is the largest energy source accounting for about 39\% of fossil energy followed by coal at 33\% [2]. The use of petroleum with its consequent environmental hazards has necessitated the search for alternative energy sources that would reduce or stop environmental pollution and still meet the needs of consumers [3]. This quest for better alternatives to fossil fuel have given rise to ecofriendly sources of energy like hydrogen, wind, solar, geothermal and biodiesel [4]. Biodiesel is a fuel composed of mono-alkyl esters of long chain fatty acids derived from the renewable vegetable oils or animal fats $[5,6]$. Vegetable oils and animal fats are principally

composed of triacylglycerol (TAG) consisting of long chain fatty acids chemically bound to a glycerol backbone. The chemical process by which biodiesel is prepared is known as transesterification [7]. Biodiesel is compatible with conventional diesel fuel and has drawn lots of attention in the last decade because it is renewable and non-toxic.

Despite the advantages of biodiesel, it is still more expensive than petroleum diesel. The major obstacle in the commercialization of biodiesel production from edible oil, is its high production cost, due mainly to the high cost of the edible oils [7]. Waste cooking oil, which is less expensive than edible oil, is a promising alternative. The trend therefore in biodiesel research is the production of biodiesel that is cheaper than petroleum diesel [8]; this can be achieved by optimizing the process parameters. In this study WCO obtained from fast food outlets which is usually thrown away is used as a feed stock for production of biodiesel in a separatory funnel.
\end{abstract}


Disposal of the WCO is expensive and could be an environmental problem, when improperly done but this could be abated by converting the waste cooking oil to biodiesel [9]. The production cost of WCOMe per litre was therefore evaluated and compared to that of palm kernel oil methyl ester [PKOMe].

\section{Materials and Method \\ Sample collection}

The waste cooking oil used for this study was obtained from a roadside fast food vendor who fries baked beans, yam, potatoes, etc. at Aluu, Port Harcourt, Rivers State. Nigeria; the palm kernel oil [PKO] was also purchased from the road side fast food vendor.

\section{Pretreatment}

WCO [500ml] was pretreated by filtering, and filtrate washed with $\mathrm{NaCl}$ solution [50\% in water; $50 \mathrm{ml} \times 2$ ]. The upper layer was collected and washed with $\mathrm{H}_{2} \mathrm{O}$ [50ml x 3] in a separatory funnel and dried at $105{ }^{\circ} \mathrm{C}$ for $2 \mathrm{hr}$.

\section{Transesterification}

The pretreated WCO [100 ml] was placed in a separatory funnel with $\mathrm{KOH}$ solution $[2 \mathrm{ml}$ of $100 \%$ solution] and methanol [10 ml]. The mixture was agitated continuously for 30 mins and allowed to settle (forming two layers) after $24 \mathrm{hrs}$. The lower dark glycerol layer was drained off, leaving the upper light yellow biodiesel [WCOMe] layer which was washed with distilled water $(10 \mathrm{ml} \times 5)$. The WCOMe was dried by filtering it through a short column of anhydrous sodium sulphate and placed in an oven at $105{ }^{\circ} \mathrm{C}$ for $1 \mathrm{hr}$ to afford a yield of $96 \%$. The yield was computed from the formula; $100 \times \mathrm{V}_{\text {wcome }} / \mathrm{V}_{\text {wco. }}$.

The procedure for WCOMe was repeated for PKOMe, except for the initial pretreatment and the production cost for the two esters compared based on cost of feed stock only, since all other process parameters were the same. The presence of fatty acids were confirmed by GC as shown in table 2; while the fuel quality parameters were determined by a slight modification to standard procedures. Viscosity was determined by passing the sample through a capillary tube and noting the time it took for the sample to flow from point A-B [54 cm]. For cloud point the oil $[5 \mathrm{ml}]$ was placed in a test tube with a thermometer $\left[-20{ }^{0} \mathrm{C}\right.$ to $100{ }^{\circ} \mathrm{C}$ range $]$ and the test tube placed in an ultra-low

Table 1 showing yield and fuel quality parameters of WCOMe and other biodiesels

\begin{tabular}{|c|c|c|c|c|c|c|}
\hline Parameters & wCOMe & WCO & $\begin{array}{l}\text { Rape seed oil } \\
\text { methyl esters }\end{array}$ & $\begin{array}{l}\text { Canola seed oil } \\
\text { methyl esters }\end{array}$ & $\begin{array}{l}\text { PKO seed } \\
\text { methyl } \\
\text { esters }\end{array}$ & $\begin{array}{l}\text { D2 } \\
\text { petroleum } \\
\text { diesel }\end{array}$ \\
\hline Biodiesel yield[\%] & 96 & - & - & - & 96 & - \\
\hline Colour & $\begin{array}{l}\text { Golden } \\
\text { yellow }\end{array}$ & Dark & - & - & Dark yellow & $\begin{array}{l}\text { Dark } \\
\text { yellow }\end{array}$ \\
\hline Viscosity[secs] & 29.8 & 36.85 & - & - & 28 & 10.27 \\
\hline Flash point $\left[{ }^{\circ} \mathrm{C}\right]$ & 240 & 320 & 124 & 177 & 170 & 74 \\
\hline Cloud point $\left[{ }^{0} \mathrm{C}\right]$ & 1.0 & 5.0 & - & -1 & 6 & -12 \\
\hline Pour point $\left[{ }^{\circ} \mathrm{C}\right]$ & 0.8 & 8.0 & - & -10 & 2 & -16 \\
\hline $\begin{array}{l}\text { Specific gravity@40 } \\
{ }^{0} \mathrm{C}\end{array}$ & 0.879 & 0.98 & 0.876 & 0.878 & 0.88 & 0.853 \\
\hline
\end{tabular}

temperature refrigerator $\left[-50{ }^{\circ} \mathrm{C}\right]$. The temperature when cloudiness appeared was noted as cloud point. The oil in the test tube was then allowed to freeze and the test tube inverted and the temperature at which the oil started to flow recorded as the pour point. The flash point was determined by placing the sample $[10 \mathrm{ml}]$ in a 25 $\mathrm{ml}$ beaker which was placed on a hot plate. The vapour above the oil was ignited after every 2 min and the temperature at which the vapour ignited noted as the flash point. The cost of PKO per litre was $\mathrm{N} 500$ and that of WCO $N 0.0 \mathrm{~L}^{-1}$. This data was used in calculating the production cost of 1 litre of biodiesel as $\$ 520.83 \mathrm{~L}^{-1}$ for PKOMe while it was $\mathrm{N} 0.0 \mathrm{~L}^{-1}$ for WCOMe; based only on the feedstock price, since all the other process 
parameters were the same for PKOMe and WCOMe.

\section{Results and Discussion}

Transesterification of oils to afford biodiesel and glycerol is a well-known process [10] with the use of a homogenous or heterogeneous catalyst. However, despite the advantages of biodiesel, it is still more expensive than D2 petroleum diesel; especially those from straight vegetable oils. Biodiesel research is therefore presently focussed on the production of biodiesel that is cheaper than D2 petroleum diesel and usually involves the optimization of the process parameters[10]. In the present study the use of free WCO as feedstock for biodiesel production was investigated and considerably reduced the cost of the WCOMe. This was compared to the cost of producing one litre of PKOMe as $\mathrm{N} 520.83 \mathrm{~L}^{-1}$ and $\mathrm{N} 0.0 \mathrm{~L}^{-1}$ for WCOMe. The comparison was based only on feed stock price since all the other process parameters were the same for the two esters.

The reaction took place at atmospheric pressure and a temperature of $40^{\circ} \mathrm{C}$ with vigorous agitation for 30 mins in a separatory funnel after which it was allowed to stand overnight, leaving two layers. Top light yellow biodiesel layer and darker coloured lower glycerol layer. The glycerol layer was drained off and distilled water used to wash the biodiesel layer $(10 \mathrm{ml} \times 5)$ by swirling gently (to avoid emulsion formation). The formation of inseparable emulsions is a major work up problem in biodiesel production, especially with homogenous catalysts like $\mathrm{NaOH}$ or $\mathrm{KOH}$. The washing was stopped when the aqueous layer became clear and the biodiesel was subsequently dried by passing it through a short column of anhydrous sodium sulphate. The washing with water removes traces of methanol, soap and glycerol in the biodiesel layer. The glycerol can be recovered by vacuum distillation and used in several cosmetic products. Production under atmospheric conditions will relatively reduce the cost of the biodiesel.

Excess potassium hydroxide catalyst mixture was used to serve a dual purpose; one, neutralize excess free fatty acid present in the WCO and the other, drive the reaction in the forward direction. As seen in Table 1, WCO is more viscous than WCOMe and D2 petroleum diesel. The fatty acid profile [table 2] [8] shows the presence of saturated and unsaturated fatty acids in the WCO and PKO. For the WCO, this cannot be taken as representative since the $\mathrm{WCO}$ is a mixture of oils from different sources. The flash point shows WCOMe is safer to handle than D2, while the cloud and pour points show the WCOMe to be suitable for use in warm equatorial countries like Nigeria as B100. For temperate countries blending can permit its usage as B5 or B20 fuels $[9,10,11,12,13]$.

\begin{tabular}{|c|c|c|}
\hline Fatty acid & $\mathrm{COMe}[\%]$ & PKOMe[\%] \\
\hline Caproic, C6:0 & - & 0.9 \\
\hline Caprylic, C8:0 & - & 5.0 \\
\hline Capric, C10:0 & - & 4.4 \\
\hline Lauric, C12:0 & 15.0 & 51.0 \\
\hline Myristoleic, C14:1 & 14.8 & 16.8 \\
\hline Stearic, C18:0 & 20.4 & - \\
\hline Oleic, C18:1 & 35.5 & 16.4 \\
\hline Linoleic, C18:2 & - & 3.4 \\
\hline Unidentified & 14.3 & 0.9 \\
\hline
\end{tabular}

\section{Conclusion}

This study clearly shows that biodiesel can be prepared on a laboratory scale, using cheaper waste cooking oil as feed stock under atmospheric conditions to afford relatively cheaper biodiesel than those from virgin oils and D2 diesel. In addition, this study has also shown that the agitation method used in production of biodiesel from the laboratory scale production is faster, cheaper and efficient. This study also provides a proper outlet for WCO by reducing its environmental risk from improper disposal.

\section{References}

1. AR4 Climate Change: S. Solomon, D. Qin, M. Manning, Z. Chen, M. Marquis, K.B. Averyt, M. Tignor and H.L. Miller (eds.)]. (2007). Intergovernmental Panel on Climate Change [IPCC] Climate Change 2007: The Physical Science Basis. Contribution of Working Group I to the Fourth Assessment Report of the Intergovernmental Panel on Climate Change, 
Cambridge University Press, Cambridge, United Kingdom and New York, NY, USA.

2. BP (2014). Statistical Review of World Energy. World Petroleum Congress, Moscow. pp1-5.

3. F. Lun, J. Liu, P. Ciais,T. Nesme, J. Chang, R. Wang, D. Goll, J. Sardans, J. Peñuelas, and, M. Obersteine [2018]: Global and regional phosphorus budgets in agricultural systems and their implications for phosphorus-use efficiency, Earth Syst. Sci. Data, 10, 1-18, https://doi.org/10.5194/essd-10-1-2018.

4. A. Demirbas [2017] Energy Sources, Part A: Recovery, Utilization, and Environmental Effects; Tomorrow's biofuels: Goals and hopes. Volume 39, Issue 7. 673-679|

5. U.S. Energy Information Administration[EIA] [2018], Monthly Energy Review, Environment, May 2019, preliminary data. 1-272

6. M. Branco-Vieiraa, D. Costac, T.M. Mataa, A.A. Martinsa, M.A.V. Freitasb, N.S. Caetanoa [2020] A life cycle inventory of microalgae-based biofuels production in an industrial plant concept. Energy Reports 6. 397-402.

6th International Conference on Energy and Environment Research, ICEER 2019, 22-25 July. University of Aveiro, Portugal.

7. ETIP Bioenergy-SABS [2004] Biodiesel Production Technology, National Renewable Energy Laboratory, July 2004 (NREL/SR-51036244). Accessed 29 July 2020.

8. J. Poudel, S. Karki. N. Sanjel, M. Shah, and S. Cheon Oh[2017], Comparison of Biodiesel Obtained from Virgin Cooking Oil and Waste Cooking Oil Using Supercritical and Catalytic Transesterification Energies, 10, p546; doi:10.3390/en10040546

9. R. D. Saini [2017] Conversion of Waste Cooking Oil to Biodiesel International Journal of Petroleum Science and Technology Volume 11, Number 1, pp. 9-21.

10. E. de A. S. Braga, J.de Q. Malveira, M. Aparecida, L. Milhome, M. D. de Aquino, and R.
F. do Nascimento[2015] Journal of Chemistry; Characterization of the Fatty Acids Present in Wastewaters from Production of Biodiesel Tilapia. / Volume 2015 |Article ID 265160 | 6 pages | https://doi.org/10.1155/2015/265160

11. L. J. Lee, and E. J. Hammond. (1996) Reducing the crystallization temperature of biodiesel by winterizing methyl soyate. Journal of the American Oil Chemists Society 73(5):631-636.

12. M. Mittelbach, and C. Remschmidt[ed] (2005) Biodiesel the Comprehensive Handbook, Second Edition. Boersedruck Ges. m.b.H, Vienna.

13. B.R. Moser,(2008) Influence of blending canola, palm, soybean, and sunflower oil methyl esters on fuel properties of biodiesel. Energy \& Fuels 22(6):4301-4306. 